http://jmscr.igmpublication.org/home/ ISSN (e)-2347-176x ISSN (p) 2455-0450

crossref DOI: https://dx.doi.org/10.18535/jmscr/v7i9.66

Journal Of Medical Science And Clinical Research

\title{
A Prospective Study of Incidence and Management of CTEPH at Our
}

\section{Centre}

\author{
Authors \\ Dr Dhananjay Bansal ${ }^{1}$, Dr Rahul Bhushan ${ }^{2 *}$, Dr Vijay Grover ${ }^{3}$, Dr Vijay K. Gupta ${ }^{4}$ \\ ${ }^{1}$ MCh Resident, Dept of CTVS, Dr RML Hospital, New Delhi. \\ ${ }^{2} \mathrm{MCh}$ Resident, Dept of CTVS, Dr RML Hospital, New Delhi. \\ ${ }^{3}$ Consultant and HOD, Dept of CTVS, Dr RML Hospital, New Delhi \\ ${ }^{4}$ Consultant, Dept of CTVS, Dr RML Hospital, New Delhi \\ *Corresponding Author \\ Dr Rahul Bhushan
}

\begin{abstract}
Chronic thromboembolic pulmonary hypertension (CTEPH) IS defined as pulmonary hypertension (PH) caused by single or recurrent pulmonary emboli arising from deep vein thrombosis (DVT). This observational study was carried out from Sep 2018 to August 2019. The diagnosis of Chronic PTE was confirmed in 4 patients by computed tomography pulmonary angiography (CTPA). After confirming the diagnosis, the patients were started anticoagulation therapy and planned for surgical endarterectomy. CT angio was also performed in post op period which suggested no residual thrombus in 2 pts while mildmoderate distal residual segmental artery thrombus in 2 patients. Our Experience suggests surgical intervention rather than anti coagulation is effective definitive and ideal management for pateints of CTEPH. Early recognition, aggressive appropriate treatment and systematic follow-up can improve the outcome of this potentially fatal condition.
\end{abstract}

\section{Introduction}

CTEPH caused by chronic obstruction of major pulmonary arteries. It is Amenable to cure by pulmonary endarterectomy (PEA) roughly around $\approx 5$ individuals per million per year get affected but lack of clinical suspicion and delay in diagnosis leads to under detection of this disease to a great extent.

Chronic thromboembolic pulmonary hypertension (CTEPH) IS defined as pulmonary hypertension $(\mathrm{PH})$ caused by single or recurrent pulmonary emboli arising from deep vein thrombosis (DVT). These embolic events are not always clinically apparent. In such cases, a silent acute pulmonary embolism (PE) is the initiating event, and subsequent pulmonary vascular remodelling (small vessel disease) causes progression to $\mathrm{PH}$. By a mechanism that is poorly understood, this chronic obstructive disease may lead to a small vessel arteriolar vasculopathy characterized by excessive smooth muscle cell proliferation around small arterioles in the pulmonary circulation. This small vessel vasculopathy is seen in the remaining open vessels, which are subjected to long exposure at high flow. Pulmonary hypertension results when the capacitance of the remaining open bed cannot absorb the cardiac output - because of either the 
degree of primary obstruction by embolus or the combination of a fixed obstructive lesion and secondary small vessel vasculopathy.

Although the understanding of the natural history of acute PTE and its evolution to CTEPH, and pathophysiology of CTEPH have greatly improved, the true frequency of CTEPH is likely under-estimated. There is a paucity of data about the incidence and prevalence of CTEPH from the Indian sub-continent. We investigated the clinical profile of acute PTE and the incidence of CTEPH over a one-and-a-half-year follow-up in a tertiary care cardiology hospital in Southern India

\section{Materials and Methods}

This observational study was carried out from Sep 2018 to August 2019. There was a total of 12 patients who were suspected to have Chronic PTE. The suspicion was based on the clinical scenario and the Wells pretest probability scoring system. The diagnosis was based on pts following up after episode of Acute DVT on anti-coagulation presenting with clinical signs and symptoms of acute onset dyspnoea, orthopnoea, chest pain, haemoptysis and a loud second heart sound. The diagnosis of Chronic PTE was confirmed in 4 patients by computed tomography pulmonary angiography (CTPA). After confirming the diagnosis, the patientswere started anticoagulation therapy and planned for surgical endarterectomy as guided by literature suggesting surgical exploration as only definitive treatment and a Class 1 recommendation in guidelines.

Intra-operatively, midline sternotomy was performed and patients were electively taken on bypass with cardioplegia for better field of vison and complete thrombus evacuation. MPA was exposed at bifurcation and incision extended to RPA and LPA separately. Pleura was not breached in any case. Complete thrombus extraction till its "Tail" was performed.

Total bypass on average was 45 mins. Post op was uneventful in 3 patients except 1 patient requiring prolonged ventilation with evidence of pulmonary oedema in post op interval which was successfully managed conservatively.

CT angio was also performed in post op period which suggested no residual thrombus in 2 pts while mild- moderate distal residual segmental artery thrombus in 2 patients. 2 Patients with significant TR and RV dysfunction also improved significantly in post op interval with residual RVSP of 22 on average in all 4 patients.

\section{Discussion}

By a mechanism that is poorly understood, this chronic obstructive disease may lead to a small vessel arteriolar vasculopathy characterized by excessive smooth muscle cell proliferation around small arterioles in the pulmonary circulation. This small vessel vasculopathy is seen in the remaining open vessels, which are subjected to long exposure at high flow. Pulmonary hypertension results when the capacitance of the remaining open bed cannot absorb the cardiac outputbecause of either the degree of primary obstruction by embolus or the combination of a fixed obstructive lesion and secondary small vessel vasculopathy.

The three major reasons for considering a patient for pulmonary endarterectomy are hemodynamic, respiratory, and prophylactic. The hemodynamic goal is to prevent or ameliorate right ventricular compromise caused by pulmonary hypertension. The respiratory objective is to improve function by the removal of a large ventilated but unperfused physiological dead space.

The prophylactic goals are to prevent progressive right ventricular dysfunction, retrograde extension of the clot, and the prevention of secondary vasculopathic changes in the remaining patent vessels. Pulmonary endarterectomy is considered in patients who are symptomatic and have evidence of hemodynamic or ventilatory impairment at rest or with exercise There is no upper limit of PVR level, pulmonary artery pressure, or degree of right ventricular dysfunction that excludes patients from operation. For those with milder pulmonary hypertension, 
the decision to operate is based on individual circumstances.

Our experience with surgical exploration and thrombus extraction was satisfactory with good outcome and symptomatic improvement in all 4 patients been operated for CTEPH with no significant post op morbidity thus suggesting and reaffirming the fact that surgery is the only definitive treatment of CTEPH while role of prolonged anticoagulation therapy is only supportive to primary therapeutic goal of disease elimination.

\section{Conclusions}

Acute pulmonary embolism is an underrecognised but likely common clinical problem in India. A high index of clinical suspicion is necessary to diagnose it and confirm on computed tomographic pulmonary angiography. Our Experience suggests surgical intervention rather than anti coagulation is effective definitive and ideal management for patients of CTEPH. Early recognition, aggressive appropriate treatment and systematic follow-up can improve the outcome of this potentially fatal condition

\section{References}

1. Parakh R, Kapadia SR, Sen I, Agarwal S, Grover T, Yadav A, et al. Pulmonary embolism: a frequent occurrence in Indian patients with symptomatic lower limb venous thrombosis. Asian J Surg 2006; 29:86-91.

2. Moor GF, Sabiston DC Jr. Embolectomy for chronic PE and pulmonary hypertension. Rev Surg1969;26:449-51.

3. Piazza G, Goldhaber SZ. Chronic thromboembolic pulmonary hypertension. N Engl J Med 2011;364:351-60.

4. Nakajima N, Masuda M. The surgical treatment for chronic pulmonary thromboembolism: our experience and current review of the literature. Ann Thorac Cardiovasc Surg1997;3:15-21
5. Fedullo PF, Auger WR, Kerr KM, Rubin LJ. Chronic thromboembolic pulmonary hypertension. N Engl J Med 2001; 345:1465-72.

6. Becattini C, Agnelli G, Pesavento R, Sillingardi M, Poggio R, Taliani MR, et al. Incidence of chronic thromboembolic pulmonary hypertension after a first episode of pulmonary embolism. Chest 2006;130:172-5.

7. Pengo V, Lensing AW, Prins $\mathrm{MH}$, Marchiori A, Davidson BL, Tiozzot F, et al. Incidence of chronic thromboembolic pulmonary hypertension after pulmonary embolism. N Engl J Med 2004;350:225764.

8. Wilkens H, Lang I, Behr J, Grohe C, Guth $\mathrm{S}$, Hoeper $\mathrm{MN}$, et al. Chronic thromboembolic pulmonary hypertension (CTEPH): Updated Recommendations of the Cologne Consensus Conference 2011. Int J Cardiol 2011;154 (Suppl.): 554-60.

9. Hoeper MM, Mayer E, Simonneau G, et al. Chronic thromboembolic pulmonary hypertension. Circulation 2006;113:201120.

10. Azarian R, Wartski M, Collingnon MA, Parent F, Herve P, Sors H, et al. Lung perfusion scans and hemodynamics in acute and chronic pulmonary embolism. J Nucl Med 1997;38:980-3. 